\title{
Adverse Childhood Experiences and Avatar Preferences in Online Games
}

\author{
Results from a Population-Based Survey in Germany \\ Oswald David Kothgassner ${ }^{1}$, Paul L. Plener ${ }^{1,2}$, Cedric Sachser², Andreas Witt ${ }^{2}$, Elmar Brähler ${ }^{3}$, \\ and Jörg Michael Fegert²
}

\author{
Department of Child and Adolescent Psychiatry, Medical University of Vienna, Austria \\ Department of Child and Adolescent Psychiatry/Psychotherapy, University of Ulm, Germany \\ Department of Psychosomatic Medicine and Psychotherapy, University Medical Center of the Johannes Gutenberg University \\ of Mainz, Germany
}

\begin{abstract}
This study investigates the relationship between adverse childhood experiences (ACEs), age, and sex with respect to their avatar preference in online games. The analyses comprise a subsample of $n=1817$ adolescents and adults from 14 to 60 years within a representative German population-based study. Results indicate that $14 \%$ of this sample uses avatars in online games, with significantly more males (22.6\%) than females (7.7\%) doing so. Persons with multiple ACEs ( $\geq 4)$ have a higher OR of 2.05 (95\% Cl: 1.418-2.956) to use avatars in online games. Regarding avatar preference, females are more likely to play supporters than males, and males are more likely to choose damagers and mixedtype avatars than females. Participants with an experience of parental divorce during their childhood reported higher preference of playing supporter or mixed-type avatars in comparison with damager avatars. Moreover, participants with mental illness or suicide in the family show a higher preference of mixed-type avatars compared to damager, but not to supporter avatars. Knowledge about the use of avatars can be an interesting source of information for supporting psychotherapeutic treatment in a young age group.
\end{abstract}

Keywords: avatars, adverse childhood experiences, online games, childhood trauma, parental separation

\section{Belastende Kindheitserfahrungen und Avatarpräferenz in Online-Spielen: Ergebnisse einer repräsentativen Erhebung in Deutschland}

Zusammenfassung: Die vorliegende Studie untersucht den Zusammenhang zwischen belastenden Erfahrungen in der Kindheit (ACEs), Alter und Geschlecht in Bezug auf die Avatarpräferenz in Online-Spielen. Ein repräsentatives deutsches Subsample von $n=1817$ Jugendlichen und Erwachsenen zwischen 14 und 60 Jahren wurde dazu analysiert. Die Ergebnisse zeigen, dass 14\% der untersuchten Personen Avatare in Online-Spielen nutzen, insbesondere berichteten signifikant mehr Männer (22.6\%) als Frauen (7.7\%) Avatare zu nutzen. Darüber hinaus zeigten Personen mit multiplen ACEs ( $\geq 4)$ eine erhöhte OR (2.05, 95\% KI: 1.418-2.956) Avatare zu nutzen. Frauen geben zudem öfter an SupporterAvatare zu spielen, während Männer eher Damager- und Mixed-type-Avatare angaben. Personen, welche elterliche Scheidungserfahrungen durchlebt haben gaben eine höhere Präferenz für Supporter- und Mixed-type Avataren an, während Personen mit psychischen Erkrankungen oder Suizid in der Familie eher Mixed-type Avatare verwenden. Die Ergebnisse hinsichtlich Avatarnutzung stellen einen wertvollen Beitrag zur Unterstützung psychotherapeutischer Behandlung im Kindes- und Jugendalter dar.

Schlüsselwörter: Avatare, belastende Kindheitserfahrungen, Online-Spiele, Kindheitstraumata, Trennung

\section{Introduction}

Adverse childhood experiences (ACEs), which can be understood as an umbrella term for both child abuse and neglect as well as further dysfunctions in the household during one's upbringing (Felitti et al., 1998) are a predictor of both an adverse psychosocial (Fergusson et al., 2008; Karatekin et al., 2018) and somatic outcome (Clemens et al. 2018; England-Mason et al., 2018; Felitti et al., 1998; Wegman \& Stetler, 2009) in adulthood. Given the well-described association between these early adverse experiences and detrimental outcomes later in life, the number of those reporting adverse experiences is still alarmingly high. In a recent representative study of the German population, $2.6 \%$ reported having experienced severe emotional abuse, $3.3 \%$ severe physical abuse, $2.3 \%$ severe sexual abuse, $7.1 \%$ severe emotional neglect, and $9 \%$ severe physical neglect throughout their childhood (Witt et al., 2017).

Internet gaming disorder is also a common phenomenon among German adolescents, with $5.7 \%$ of 12- to 25-year-olds fulfilling criteria (Wartberg et al., 2017a); this will be included in ICD-11 as a formal diagnosis. Internet 
gaming disorder has been shown to be associated with family dysfunction (Bonnaire \& Phan, 2017; Schneider et al., 2017) and parental mental health (Wartberg et al., 2017b).

The model of compensatory internet use (KardefeltWinther, 2014) suggests that the experience of adversarial situations in offline reality can be a prominent motivational factor for online interaction. These interactions allow the individual to cope with negative mood, rejection, or frustration. Therefore, it seems valuable to explore associations between ACEs and online use. The lack of coping resources for psychosocial harm in a person's real life may lead to an engagement in online social interaction and alternative narratives of life (Griffith et al., 2016; Stetina et al., 2011). Especially, massively multiplayer online role-playing games (MMORPGs) provide a persistent interaction among people playing these games ( $\mathrm{Ng} \&$ Wiemer-Hastings, 2005). These people create digital representations of themselves that allow for interaction with others. These virtual characters are called avatars, representing the individual within the online game and enabling the interaction with the game itself and other players. According to the literature, these avatar classes were clustered regarding their distinctive abilities to fulfill a particular role in a group-play formation. Therefore, healing and tanking abilities of ones' avatar can be seen as (social) supportive attitudes, while damage dealing reflects a more aggressive attitude, inflicting a high degree of damage and destruction on others. Nevertheless, some avatars show hybrid - so-called mixedtype-abilities and are able giving support as well as dealing damage (Bergstrom, Jenson, \& de Castell, 2012).

However, creating an avatar is often a complex task, since avatars are often grouped in classes with special, predefined abilities, strengths, and weaknesses, and the preference for a particular avatar class seems to reflect the biographical attitude, the profile of the actual or ideal self, and the personality traits of the person playing (Bessier et al., 2007; Dunn \& Guadagno, 2012; Lin \& Wang, 2014; Mancini \& Sibilla, 2017). The preference for an avatar or an avatar class depends on intrapersonal traits (e.g., Dunn \& Guadagno, 2012; Mancini \& Sibilla, 2017; McCreery et al., 2012), and in turn the use of these virtual characters affects peoples' subsequent behavior (e.g., Fox et al., 2013; Van der Heide et al., 2009; Yee \& Bailenson, 2007; Yee, Bailenson \& Duchneaut, 2009). This can be explained by the socalled Proteus effect, which states that people embody expected attributes of an avatar with a salient social identity, which then affects their behavior (Yee \& Bailenson, 2007). Conversely, further research concerns which factors predict the preference for specific attributes in avatar creation. According to theoretical considerations in the literature, avatars represent prosthetic limbs (Veerapen, 2011), forecasts of the player's characteristics that seem essential for the purpose of the online game (McCreary et al., 2012), or as primary virtual replications or extensions of a person - or an externalization of the self (Gee, 2003; Turkle, 1997). This means that an avatar appears mostly as a manifestation of the self, but then conveys it beyond the realm of the individual's offline reality. According to Gee (2003), each avatar of a person represents a slice of a collective self, and each avatar becomes part of the person's overall identity. Similarly, Bessier and colleagues (2007) suggest understanding avatars as psychologically connected entities, reflecting the individual's actual self or ideal self, a reference to the self-discrepancy theory by Higgins (1987). Especially people with low self-esteem create avatars near to their ideal selves, as a form of compensation. This is further in line with the work of Dunn and Guadagno (2012), which indicates that people are likely to choose their avatars in order to compensate for perceived personality shortcomings, like low self-esteem or introversion.

To date, besides research relating online gaming with psychopathology, such as addictive gaming behavior, social anxiety, and depression (Caplan et al., 2009; Stetina et al., 2011; Williams et al., 2008), there is a lack of knowledge regarding the relationship between avatar usage and mental health and personality issues. Furthermore, given that the exposure to adverse life experiences in childhood is directly associated with subsequent mental disorders (Anda et al., 2006), it is still unclear what avatar preference as a concept of an individual's personality in online games plays with regards to coping with and reacting to adverse childhood experiences.

Given the fact that extensive online gaming is highly associated with problems in real life, especially regarding the management of stress, anger, and frustration (KardefeltWinther, 2014), it is of growing interest to develop a better understanding on the influence of online games to current life situations. This study describes the relationship of avatar preferences and adverse childhood exposures (research question 1) in a representative German sample of the potentially gaming population. The proportion of avatar users are compared with the sample without an avatar. Additionally, potential factors that might be related to avatar preferences, such as age, sex, and time spent within the online game (research questions 2-4) are explored. Moreover, the predictive value of ACEs for the preference for specific avatars are investigated (research question 5 ).

\section{Methods}

\section{Procedure}

Using a random-route procedure, a representative sample of the German population was acquired by a social research 
institute (USUMA, Berlin, Germany) between November 2017 and February 2018. Households of every third residence in a randomly chosen geographical area were invited to participate in the study. In multiperson households, participants were randomly selected using a Kish Selection Grid. Inclusion criteria were a minimum age of 14 years and sufficient knowledge of the German language. Of the 4,902 designated addresses, 2,531 households participated in the study $(49.7 \%)$. Given that online gaming use was very low in participants above the age of 60, we restricted our sample to participants between the ages of 14 and $60(n=1,823)$. Responses were anonymous. In a first step, sociodemographic information was gathered by research staff using an interview format. All other information was obtained via paper-and-pencil questionnaires, with research staff being available for questions.

The study was conducted in accordance with the Declaration of Helsinki and fulfilled the ethical guidelines of the International Code of Marketing and Social Research Practice of the International Chamber of Commerce and of the European Society of Opinion and Marketing Research. All participants (and, if applicable, their caregivers) gave informed written consent. The study was approved by the Ethics Committee of the Medical Department of the University of Leipzig.

\section{Participants}

A total of 1,817 persons ranging from 14 to 60 years within a population-based German sample were chosen for final analysis. This representative subsample with a mean age of 40.1 years $(S D=13.007)$ consisted of $811(44.5 \%)$ males and 1,011 (55.5\%) females.

In this sample, $42.9 \%$ were married, $42.8 \%$ were not living in a partnership, $1.5 \%$ were widowed, and $12.3 \%$ were divorced. Further, $23.3 \%$ had finished less than a highschool education, $38.6 \%$ had finished a secondary school, $14.8 \%$ had achieved the matriculation standard or equivalent, and $9.1 \%$ possessed an academic degree. The full- or part-time employment rate was $73.9 \%$; the unemployment rate was $6.5 \%, 2.6 \%$ were receiving a pension, and $11.6 \%$ were still in school or in training. More than half $(53.8 \%)$ of the monthly household income lay between EUR 750 and EUR 2,000.

From the initial sample of $N=2531$, we excluded 708 persons older than 60 years, because the distribution of avatar usage in these age groups was $n \leq 5$. Further, persons reporting more than two main avatar classes were excluded from the study $(n=1)$. Five further participants were excluded from the study because two of them did not respond to all questions as required and three failed the plausibility check. The plausibility check verified the logi- cal consistency of the participant's data. We checked age and its relationship to educational level and current employment as well as responses regarding avatar usage and specific questions to avatar preference.

\section{Measures}

Apart from a short survey assessing core demographic variables (e.g., age, sex), we assessed avatar use in online games by an adhoc questionnaire. This consisted of a question about whether avatars are used to get in contact with others in online games, how much time is spent on a weekday for online gaming, how many avatars are used, as well as which type of avatar is mainly used. Types of avatars were drawn from popular fantasy online games (such as "World of Warcraft") presenting nine types (healer, magician, warrior, helper, tank, hunter, shaman, monk, druid), which were grouped into three classes (damager, supporter, mixed-type).

Adverse childhood experiences (ACE) before the age of 18 years were assessed using the German translation of the ACE Study Questionnaire initially used by Felitti and colleagues (1998). The ACE Study Questionnaire consists of item clusters regarding child abuse and neglect, household dysfunctions, and parental separation. For the current study, we used the German validation of the ACE Questionnaire (Wingenfeld et al., 2011), with a dichotomous scale (yes/no) for each question. We used summed scores to obtain a criterion of exposures $\geq 4$ for a general burden with high risk of mental and somatic health disturbances (Anda et al., 2006).

Psychological and physical abuse items consisted of two items asking about exposure to verbal threat or vilification as well as physical punishment, primarily used in the conflict tactics scale (Strauss \& Gelles, 1990). ("Did a parent or other adult in the household [...] often or very often swear at, insult, or put you down?" and "[...] often or very often act in a way that made you afraid that you would be physically hurt?").

Sexual abuse items asked about exposure to several forms of sexual harassment or assaults. The four items were initially based on four questions by Wyatt (1985). For this study, the items were cumulatively coded to one dichotomous response for statistical analysis (e.g., "Did an adult or person at least 5 years older ever [...] touch or fondle you in a sexual way?”)

Household alcohol or drug exposure during childhood was assessed as an adapted single item version for this study taken from National Health Interview Survey (1988) ("Did you live with anyone, who was or is an alcoholic or addicted to drugs?").

Neglect was measured as a deficit in meeting a child's basic needs with a single item ("Did you ever had to go to 
school or out with friends wearing dirty clothes; or do feel that you didn't get enough to eat; or you had no one you can really rely on?").

Mental illness and suicide in the household was measured using a single item asking for general mental illness, depression, and/or suicide attempts in the family living together in the household ("Was a household member mentally ill, depressed or attempted suicide?”).

Battered mother was again a single item concerning exposure to traumatic life events regarding violence against the mother or stepmother during the respondent's childhood ("Was your mother/stepmother sometimes, often, or very often pushed, grabbed, slapped, or had something thrown at her?").

Criminal behavior in the household received a single item assessing whether some member of the family had been in prison ("Did a household member go to prison?").

Parental separation or divorce was assessed by "Did you ever lost a biological parent due to divorce of your parents or your parents becoming separated?"

\section{Statistical Analysis}

Statistical analyses were carried out using IBM SPSS version 23 (SPSS, Inc., Chicago, USA). We used chi-square tests and OR to describe categorical data and compare proportions of specific avatar preferences among ACEs, sex, or time, respectively. Analysis of variance (ANOVA) was conducted to analyze avatar preferences regarding age. Further, a multinomial logistical regression analysis was carried out to investigate a predictor model for avatar preferences including ACEs, sex, age, and time as predictor variables. Participants with missing data on a variable were excluded from the analysis of that specific variable.

\section{Results}

About $86.0 \%(n=1563)$ of all participants reported never having played an online game using an avatar. Thus, only a minority of participants $(14 \%)$ reported using avatars according to the classification specified above. The most commonly used class of avatars were damagers $(n=155$, $8.5 \%)$. Further, $3 \%(n=54)$ of the participants used supporters and $2.5 \%(n=45)$ using mixed-type avatars.

\section{Adverse Childhood Experience (ACE)}

Our first research question targets the relationship between preference for an avatar class and ACEs as measured by the German version of the ACE Study Question- naire (Wingenfeld et al., 2011). The score on the ACE Study Questionnaire was indexed as a high-risk indicator for mental disorders using a cutoff criterion of $\geq 4$ (Anda et al., 2006). We compared the ACE values (low risk $<4 \geq$ high risk) of participants without avatars in relation to avatar usage and different avatar preferences (supporter, damager, mixed-type).

Results indicate that persons with ACEs $\geq 4$ (10.4\%) show a 2.05 times higher rate (95\% CI 1.418-2.956) of using avatars in online games than persons with ACEs $<4$ (89.6\%). This result is consistent with ACE items regarding psychological abuse (OR $=2.08,95 \%$ CI: $1.477-$ 2.920), physical abuse (OR $=1.96,95 \%$ CI: $1.320-2.900)$, alcohol or drug exposure (OR $=1.91,95 \%$ CI: $1.60-2.597)$, neglect $(\mathrm{OR}=1.54,95 \%$ CI: 1.099-2.164), mental illness or suicide in the family (OR $=1.60,95 \%$ CI: $1.095-2.334)$, battered mother (OR $=1.73$, $95 \%$ CI: $1.172-2.555)$ as well as parental separation (OR $=2.67,95 \%$ CI: $1.235-2.253)$. Additionally, Table 1 reports OR according to avatar preference (supporter, damager, mixed-type) in comparison to the non-avatar user population, indicating that persons with ACEs $\geq 4$ more often use damagers or mixed-type avatars, while persons exposed to alcohol or drug abuse in the household, parental separation, or neglect more often report to use supporters. Further, persons with a history of mental illness or suicide in the family more often refer to the usage of a mixed-type avatar.

\section{Age}

Concerning research question 2, there is a significant difference regarding age when comparing the four groups of avatar preference: using no avatar, a supporter, a damager, or a mixed-type avatar $\left(F_{(3,1816)}=50.724, p=.000\right)$. Following a significant Levene-Test indicating heterogeneous variances, we used an ANOVA with Tamhane T2 posthoc procedure for pairwise comparison. Posthoc tests revealed a significant difference of age between the group without an avatar (mean age: $41.5, S D: 12.740$ ) and the participants using a supporter (mean age: $34.1, S D=12.012$ ), damager (mean age: 30.2, $S D$ : 11.057), and mixed-type (mean age: $30.93, S D=12.164)$ avatar $(p=.000)$, respectively. There was no statistically significant difference between the three avatar groups concerning age ( $p=.210-.998)$.

\section{Time Spent with the Avatar}

In the questionnaire, time spent with avatars was distinguished between moderate usage (1-60 min. per average day), heavy usage (60-150 min. per average day), and excessive usage (more than 150 min. per average day). Table 2 shows time spend with the avatars according to the amount of time spend for gaming with an avatar and the avatar groups. Men spent significantly more time than women with their avatars $\left(\chi^{2}=19.545, p \leq .001\right)$. 


\section{Gender Aspects}

In general, more male participants reported engaging in an online game using an avatar than females $\left(\chi^{2}=88.746\right.$, $p \leq$.001). The group reported not having had any experiences with avatars consisted of 625 male participants, representing $77.4 \%$ of all men, and 938 female participants, representing $92.9 \%$ of all women in the sample. Further, the rate ratio of playing an avatar is 3.79 times (95\% CI: 2.836-5.075) higher for men than for women. We found that one-third (33.3\%) of all female participants using an avatar reported preferring a supporter as their main virtual character, while only $16.5 \%$ of male players chose a supporter. More than half of the female players (55.6\%) chose a damager as their main avatar. Moreover, also the majority of male participants (63.2\%) chose a damager as favorable avatar class. Mixed-type avatars are played by $20.3 \%$ of men and $11.1 \%$ of women.

\section{Predictors for Avatar Preferences}

In our analysis of whether specific ACEs could influence the persons avatar preference, we performed a logistical regression model for a multinomial dependent variable using the subsample of avatar users. As shown in Table 3, all ACE scales, age group, and sex were included as predictor variables into the regression model with avatar preference as dependent variable (supporter, damager, and mixed-type).

All significant parameters from the univariate solution (mental illness or suicide in the household, parental separation and divorce) were included into a final model to test the combined contributions (see Table 4). The results showed that the overall model was statistically significant $\left(\chi_{(18)}^{2}=58.828, p \leq .001\right)$ and explained $24.5 \%$ of variance according to Nagelkerkes pseudo- $R^{2}$. The overall classification success of the model was $62.8 \%$, with $24.1 \%$ of the supporter class, $91.6 \%$ of the damager class, and $11.1 \%$ of the mixed-type class being successfully classified by the independent variables. Table 4 indicates that the participants who had experienced the divorce of their parents during childhood reported a higher preference for playing supporter or mixed-type avatars in comparison with damager avatars. Moreover, participants with

Table 2. Avatar preferences and time spent with the avatars in percent $(n=256)$

\begin{tabular}{lccc}
\hline & Supporter & Damager & Mixed-type \\
\hline Moderate usage & $44(81.5 \%)$ & $72(46.8 \%)$ & $25(55.6 \%)$ \\
Heavy usage & $8(14.8 \%)$ & $71(46.1 \%)$ & $18(40.0 \%)$ \\
Excessive usage & $2(3.7 \%)$ & $11(7.1 \%)$ & $2(4.4 \%)$ \\
\hline
\end{tabular}


mental illness or suicide in the family show a higher preference of mixed-type avatars compared to damager, but not to supporter avatars. Additionally, female sex seems to predict the preference to a supporter instead of a mixed-type, and age groups 14-19 years as well as 3039 years indicate use of damager or mixed-type avatars more often than supporter avatars. Neither moderate, heavy, or excessive usage showed a specific predictive value $(p=.073-.863)$.

Table 3. Summary of univariate predictions for avatar preference $(n=256)$

\begin{tabular}{lcc}
\hline & -2log likelihood & \multicolumn{1}{c}{$\mathrm{X}^{2}$} \\
\hline Psychological Abuse & 157,098 & 0.729 \\
Physical Abuse & 156,635 & 0.266 \\
Sexual Abuse & 157,144 & 0.775 \\
Alcohol or drug exposure & 158,832 & 2.463 \\
Neglect & 158,906 & 2.537 \\
Mental illness and suicide & 163,013 & $6.644 *$ \\
in the household & & \\
Battered mother & 156,771 & 0.402 \\
Criminal behavior & 158,443 & 2.074 \\
Parental separation and divorce & 164,928 & $8.559 *$ \\
\hline
\end{tabular}

Note. ${ }^{\star} p<.05$.

\section{Discussion}

The advent of virtual reality creates an impact on contemporary society. Especially collaborative digital places within their own narrative, such as MMORPGs, are being used as social platforms to play a virtual life creating and developing one's own virtual self - the avatar - alongside physical reality. Recent research reveals that avatar preferences seem to be predefined by the person's biography, self-concept, personality, and sex (e.g., Dunn \& Guadagno, 2012; Mancini \& Sibilla, 2017), but to date it remained unclear whether men or women, and especially individuals with a history of adverse childhood experiences, have preferences in their choice of an avatar according to its interpersonal functions and achievement potentials.

Results from this study indicate that $14 \%$ of the population-based sample reported using avatars; $71.7 \%$ of these avatar users are men and $28.3 \%$ are women. Moreover, one-third of the women use supporters, while only less than $17 \%$ of the men use this avatar class. Damagers are the most frequently used avatars, and more males than females use mixed-type avatars. Additionally, we found that individuals with multiple ACEs $(\geq 4)$ used avatar-based online games significantly more often. This is in line with prior studies showing that avatar-based MMORPGs are more often associated with a higher risk of presenting mental disorders compared to other online games (e.g., Stetina et al.,2011; Williams et al., 2008). Stetina and colleagues report that MMORPG gamers have 2-3 times higher values of depression and report lower social and emotional self-esteem. Moreover, Caplan and colleagues (2009)

Table 4. Summary of significant predictive variables after multinomial logistic regression for avatar preference $(n=256)$

\begin{tabular}{|c|c|c|c|c|}
\hline & B & SE & $\operatorname{Exp}(B)$ & $\mathrm{Cl}(95 \%) \operatorname{Exp}(\mathrm{B})$ \\
\hline \multicolumn{5}{|l|}{ Supporter vs. Damager } \\
\hline Age 14-19 & -2.079 & 0.890 & $0.125^{\star}$ & $0.022-0.716$ \\
\hline Age $30-39$ & -1.958 & 0.671 & $0.141^{* *}$ & $0.038-0.526$ \\
\hline Parental separation or divorce & 0.989 & 0.390 & $2.688 * *$ & $1.252-5.770$ \\
\hline \multicolumn{5}{|l|}{ Mixed-type vs. Damager } \\
\hline Sex & 0.919 & 0.470 & $2.506^{*}$ & $0.998-6.292$ \\
\hline Parental separation or divorce & 0.813 & 0.399 & $2.254^{*}$ & $1.032-4,925$ \\
\hline Mental illness or suicide in the household & 1.164 & 0.475 & $3.203 *$ & $1.263-8,126$ \\
\hline \multicolumn{5}{|l|}{ Supporter vs. Mixed-type } \\
\hline Sex & 1.478 & 0.519 & $4.383 *$ & $1.584-12.131$ \\
\hline
\end{tabular}

Note. For MLR, parental separation and mental health are dummy-coded as $1=$ no, $0=$ yes, sex is dummy coded as $1=$ men and $0=$ women. ${ }^{*} p<.05,{ }^{* *} p<.01$. 
found that more socially anxious persons play avatarbased MMORPGs. This may result from the fact that persons with social deficits find it easier to interact online, with a greater social distance, and in a self-created role in the shape of an avatar.

Interestingly, in our study individuals with exposure to psychological or physical abuse more often used supporters and damagers, while individuals using mixed-type avatars showed a higher likelihood to have been exposed to mental disorders in their household. Additionally, it was shown that persons with experiences of a parental separation in their childhood more often used supporters and mixed-type avatars. There is a further association between dysfunctional households, characterized by neglect as well as alcohol and drug exposure during childhood, with a higher tendency toward the use of a supporter.

Altogether, these results can be explained in the light of Higgins (1987) self-discrepancy theory. Following the assumption that avatars - as representations of the self within an MMORPG -reflect an epitome of the individual (Turkle, 1997), it can be argued that persons with multiple ACEs have high self-discrepancies in their actual and ideal self (Sutherland \& Bryant, 2008) which can be temporarily reduced by the installation of an online self - the created avatar (Klimmt et al., 2009). The avatar and with it the narrative of the MMORPG enables compensating for perceived shortcomings in real life and enables abilities and social behaviors that would be difficult to display in offline life (Dunn \& Guadagno, 2012; Rigby \& Ryan, 2011). This is further in line with the compensatory internet use model (Kardefelt-Winter, 2014), which understands online gaming behavior as a coping strategy aimed at reducing psychosocial burden. This might be an explanation for why many persons with parental separation, neglect, and experience of alcohol or drug abuse in the household choose a supporter avatar to interact within the game. Indeed, some research suggests that there is a relationship between traumatization and prosocial behavior (Frazier et al., 2012). Giving social support could also signal a recovery from a critical life-event or possible trauma and no longer being a victim to others. This could increase self-efficacy and selfesteem as well as reducing perceived stigma (Van Vugt \& Hardy, 2010). Nevertheless, according to the Proteus effect, to help someone foster social interaction, virtual support can be transformed into a real-life social behavior, which presents a positive coping strategy (Yee et al., 2009).

This study examined predictors for avatar preference. Controlling for age and time spent with the avatar, sex remains a significant predictor for choosing an avatar class. The multinomial logistic regression revealed that, compared to women, men have a higher probability of choosing damagers over mixed-type avatars $(\mathrm{OR}=2.6)$ and damager over supporter avatars $(\mathrm{OR}=4.4)$. The high- er use of purely supportive avatars in females might be due to the predominant "tend-and-befriend" pattern in female behavior, contrary to the "fight-or-flight" response in males (Taylor et al., 2000). Persons with a history of parental separation are more often likely to use supporter or mixed-type avatars $(\mathrm{OR}=2.3-2.6)$. Participants with a history of parental mental illness preferred mixed-type avatars. These two avatar types - the supporter and the mixed-type - have supportive components. Both ACEs predicting the supportive avatars have in common that they share a component of caring for others - and might indicate a learned pattern of role change in the child-parent relationship. Perhaps this role is an integrated part of the individual's self-concept which is conveyed from offline to online behavior (McCreary et al., 2012).

A definitive strength of the current study lies in the fact that it revealed a relationship between ACEs and a person's preference for their digital self - the avatar - within a population-based study. Furthermore, a strong theoretical framework, the compensatory internet use model as well as the Proteus effect, supports the results of this study. However, one limitation is that the retrospective analysis of ACEs is always affected by several biases, such as recall bias, and problems interpreting causality. Another problem is that the random route approach we used in the recruitment process systematically omits persons currently residing in institutions. Indeed, samples with high risk of abuse or neglect may be residing in welfare or healthcare institutions and thus have been underrepresented in the study.

Yet, following the above-mentioned line of thought, discussing online gaming and preferred use of certain avatars could be an interesting discussion point in psychotherapy, especially within a young age group. This is not restricted only to diagnostic use, but could also inform the therapist about idealized representations of the young patient, with the potential to provide a starting point for therapeutic change in real life.

\section{References}

Anda, R. F., Felitti, V.J., Bremner, J.D., Walker, J.D., Whitfield, C.H., Perry, B.D., ... \& Giles, W.H. (2006). The enduring effects of abuse and related adverse experiences in childhood. European Archives of Psychiatry and Clinical Neuroscience, 256, 174-186.

Bergstrom, K., Jenson, J., \& de Castell, S. (2012, May). What's' choice'got to do with it?: avatar selection differences between novice and expert players of World of Warcraft and Rift. In ACM proceedings of the International Conference on the Foundations of Digital Games (pp. 97-104). ACM.

Bessière, K., Seay, A. F., \& Kiesler, S. (2007). The ideal elf: Identity exploration in World of Warcraft. Cyberpsychology \& Behavior, 10, 530-535.

Bonnaire, C., \& Phan, O. (2017). Relationships between parental attitudes, family functioning and Internet gaming disorder in adolescents attending school. Psychiatry Research, 255, 104-110. 
Caplan, S., Williams, D., \& Yee, N. (2009). Problematic Internet use and psychosocial well-being among MMO players. Computers in Human Behavior, 25, 1312-1319.

Clemens V., Huber-Lang M., Plener P.L., Brähler E, Brown R.C., \& Fegert J.M. (2018) Association of child maltreatment subtypes and long-term physical health in a German representative sample. European Journal of Psychotraumatology, 9(1), doi 10.1080/20008198.2018.1510278

Cole, H., \& Griffiths, M.D. (2007). Social interactions in massively multiplayer online role-playing gamers. Cyberpsychology \& Behavior, 10, 575-583.

Dunn, R.A., \& Guadagno, R.E. (2012). My avatar and me: Gender and personality predictors of avatar-self discrepancy. Computers in Human Behavior, 28(1), 97-106.

England-Mason, G., Casey, R., Ferro, M., MacMillan, H.L., Tonmyr, L., \& Gonzalez, A. (2018). Child maltreatment and adult multimorbidity: results from the Canadian Community Health Survey. Canadian Journal of Public Health, 109(4), 561-572.

Felitti, V.J., Anda, R. F., Nordenberg, D., Williamson, D. F., Spitz, A. M., Edwards, V., ... Marks, J.S. (1998). Relationship of childhood abuse and household dysfunction to many of the leading causes of death in adults: The Adverse Childhood Experiences (ACE) Study. American Journal of Preventive Medicine, 14, 245-258.

Fergusson, D. M., Boden, J.M., \& Horwood, L.J. (2008). Exposure to childhood sexual and physical abuse and adjustment in early adulthood. Child Abuse Neglect, 32, 607-619.

Fox, J., Bailenson, J.N., \& Tricase, L. (2013). The embodiment of sexualized virtual selves: The Proteus effect and experiences of self-objectification via avatars. Computers in Human Behavior, 29, 930-938.

Frazier, P., Greer, C., Gabrielsen, S., Tennen, H., Park, C., \& Tomich, P. (2013). The relation between trauma exposure and prosocial behavior. Psychological Trauma: Theory, Research, Practice, and Policy, 5, 286-294.

Gee, J.P. (2003). What video games have to teach us about learning and literacy. New York: Palgrave Macmillan.

Griffiths, M.D., Kuss, D.J., Billieux, J., \& Pontes, H.M. (2016). The evolution of Internet addiction: A global perspective. Addictive Behaviors, 53, 193-195.

Higgins, E.T. (1987). Self-discrepancy: A theory relating self and affect. Psychological Review, 94, 319-340.

Karatekin, C., Almy, B., Mason, S.M., Borowsky, I., \& Barnes, A. (2018). Mental and physical health profiles of maltreated youth. Child Abuse and Neglect, 84, 23-33.

Kardefelt-Winther, D. (2014). A conceptual and methodological critique of internet addiction research: Towards a model of compensatory internet use. Computers in Human Behavior, 31 , 351-354.

Klimmt, C., Hefner, D., \& Vorderer, P. (2009). The video game experience as "true" identification: A theory of enjoyable alterations of players' self-perception. Communication Theory, 19, 351-373.

Lin, H., \& Wang, H. (2014). Avatar creation in virtual worlds: Behaviors and motivations. Computers in Human Behavior, 34, 213-218.

Mancini, T., \& Sibilla, F. (2017). Offline personality and avatar customisation: Discrepancy profiles and avatar identification in a sample of MMORPG players. Computers in Human Behavior, 69, 275-283.

Martončik, M., \& Lokša, J. (2016). Do World of Warcraft (MMORPG) players experience less loneliness and social anxiety in online world (virtual environment) than in real world (offline)? Computers in Human Behavior, 56, 127-134.

McCreery, M. P., Krach, S. K., Schrader, P.G., \& Boone, R. (2012). Defining the virtual self: Personality, behavior, and the psychology of embodiment. Computers in Human Behavior, 28, 976-983.

$\mathrm{Ng}$, B.D., \& Wiemer-Hastings, P. (2005). Addiction to the internet and online gaming. Cyberpsychology \& Behavior, 8, 110-113.
Piferi, R., Jobe, R., \& Jones, W. (2006). Giving to others during national tragedy: The effects of altruistic and egoistic motivations on long-term giving. Journal of Social and Personal Relationships, 23, 171-184.

Rigby, S., \& Ryan, R.M. (2011). Glued to games: How video games draw us in and hold us spellbound. ABC-CLIO. Santa Barbara: Greenwood Publishing.

Schneider, L.A., King, D. L., \& Delfabbro, P.H. (2017). Family factors in adolescent problematic Internet gaming: A systematic review. Journal of Behavioral Addictions, 6, 321-333.

Stetina, B.U., Kothgassner, O.D., Lehenbauer, M., \& Kryspin-Exner, I. (2011). Beyond the fascination of online games: Probing addictive behavior and depression in the world of online gaming. Computers in Human Behavior, 27, 473-479.

Straus, M., \& Gelles, J. (1990) Physical violence in American families: Risk factors and adaptations to violence in 8,145 families. New Brunswick, NJ:Transaction Press

Sutherland, K., \& Bryant, R.A. (2008). Autobiographical memory and the self-memory system in posttraumatic stress disorder. Journal of Anxiety Disorders, 22, 555-560

Taylor, S.E., Klein, L.C., Lewis, B.P., Gruenewald, T.L., Gurung, R.A., \& Updegraff, J.A. (2000). Biobehavioral responses to stress in females: Tend-and-befriend, not fight-or-flight. Psychological Review, 107, 411-429.

Turkle, S. (1997). Multiple subjectivity and virtual community at the end of the Freudian century. Sociological Inquiry, 67(1), 72-84.

Van Der Heide, B., Schumaker, E. M., Peterson, A. M., \& Jones, E. B. (2013). The Proteus effect in dyadic communication: Examining the effect of avatar appearance in computer-mediated dyadic interaction. Communication Research, 40, 838-860.

Van Vugt, M., \& Hardy, C. (2010). Cooperation for reputation: Wasteful contributions as costly signals in public goods. Group Processes and Intergroup Relations, 13, 101-111. doi $10.1177 / 1368430209342258$

Veerapen, M. (2011). Encountering oneself and the other: A case study of identity formation in Second Life. In A. Peachey \& M. Childs. Reinventing ourselves: Contemporary concepts of identity in virtual worlds (pp. 81-100). London: Springer.

Vollhardt, J.R. (2009). Altruism born of suffering and prosocial behavior following adverse life events: A review and conceptualization. Social Justice Research, 22, 53-97. doi 10.1007/ s11211-009-0088-1

Wartberg, L., Kriston, L., \& Thomasius, R. (2017a). The prevalence and psychosocial correlates of internet gaming disorder. Deutsches Ärzteblatt International, 114, 419-424.

Wartberg, L., Kriston, L., Kramer, M., Schwedler, A., Lincoln, T.M., \& Kammerl, R. (2017b). Internet gaming disorder in early adolescence: Associations with parental and adolescent mental health. European Psychiatry, 43,14-18.

Wegman, H.L., \& Stetler, C. (2009). A meta-analytic review of the effects of childhood abuse on medical outcomes in adulthood. Psychosomatic Medicine, 71, 805-812.

Wingenfeld, K., Schafer, I., Terfehr, K., Grabski, H., Driessen, M., Grabe, H., ... Spitzer, C. (2011). The reliable, valid and economic assessment of early traumatization: First psychometric characteristics of the German version of the Adverse Childhood Experiences Questionnaire (ACE). [Reliable, valide und ökonomische Erfassung früher Traumatisierung: Erste psychometrische Charakterisierung der deutschen Version des Adverse Childhood Experiences Questionnaire (ACE)]. Psychotherapie, Psychosomatik, Medizinische Psychologie, 61(1), e10-14.

Williams, D., Yee, N., \& Caplan, S.E. (2008). Who plays, how much, and why? Debunking the stereotypical gamer profile. Journal of Computer-Mediated Communication, 13, 993-1018.

Witt, A., Brown, R.C., Plener, P. L., Brähler, E., \& Fegert, J. M. (2017). Child maltreatment in Germany: Prevalence rates in the general 
population. Child Adolescent Psychiatry and Mental Health, 11, 47.

Wyatt, G. E. (1985). The sexual abuse of Afro-American and WhiteAmerican women in childhood. Child Abuse \& Neglect, 9, 507-519.

Yee, N., \& Bailenson, J. (2007). The Proteus effect: The effect of transformed self-representation on behavior. Human Communication Research, 33, 271-290.

Yee, N., Bailenson, J. N., \& Ducheneaut, N. (2009). The Proteus effect: Implications of transformed digital self-representation on online and offline behavior. Communication Research, 36, 285-312.

\section{History}

Manuscript submitted: 10.09.2018

Accepted after revision: 27.12.2018

Published online: 19.02.2019

\section{Conflict of Interest}

PLP received research funding from the German Federal Institute for Drugs and Medical Devices (BfArM), the German Federal

Ministry of Education and Research (BMBF), the Innovationsfonds,

Baden-Wuerttemberg Foundation, Volkswagen Foundation, Lundbeck and Servier. He received a speaker's honorarium from Shire.
Over the last 5 years JMF has received research funding from the EU, the DFG (German Research Foundation), the BMG (Federal Ministry of Health), the BMBF (Federal Ministry of Education and Research), the BMG (Federal Ministry of Health), the BMFSFJ (Federal Ministry of Family, Senior Citizens, Women and Youth), the BMVg (Federal Ministry of Defense), several state ministries of social affairs, the State Foundation of Baden Württemberg, the UBS Foundation, Pontifical Gregorian University, Caritas, Diocese of Rottenburg-Stuttgart. Moreover, he received travel grants, honoraria, and sponsoring for conferences and medical educational purposes from the DFG, the AACAP, the NIMH/NIH, the EU, Pro Helvetia, Janssen-Cilag (J\&J), Shire, several universities, professional associations, political foundations as well as German federal and state ministries. Every grant and every honorarium was declared to the law office of the University Hospital UIm.

\section{Univ.-Prof. Dr. Paul L. Plener, MHBA}

University Hopsital for Child and Adolescent Psychiatry Medical University of Vienna

Währingerstraße 18-20

1090 Vienna

Austria

paul.plener@meduniwien.ac.at 